\title{
The Chemical Properties of Air-water Discharge Induced by Double Die- lectric Barrier Discharge
}

\author{
Liu Kun*, Liao Hua and He Wei
}

The State Key Laboratory of Power Transmission Equipment \& System Security and New Technology, Chongqing University, Chongqing, 400044, P.R. China

\begin{abstract}
A set of air-water discharge induced by double DBD device has been designed to obtain hydrogen peroxide $\left(\mathrm{H}_{2} \mathrm{O}_{2}\right)$ and ozone $\left(\mathrm{O}_{3}\right)$ levels, simultaneously. How the $\mathrm{H}_{2} \mathrm{O}_{2}$ and $\mathrm{O}_{3}$ are being produced, which have extensively been studied by different experimental approaches such as air cooling, atomization amount, voltage applied, $\mathrm{pH}$ value and electrical conductivity (EC). The experimental results show that with the increase of atomization amount, $\mathrm{O}_{3}$ output reduced slightly, while in the start $\mathrm{H}_{2} \mathrm{O}_{2}$ output increased that later decreased. On applying high voltages, $\mathrm{O}_{3}$ output raised from $26 \mathrm{kV}$ to $32 \mathrm{kV}$, which later decreased from $32 \mathrm{kV}$ to $34 \mathrm{kV}$, in addition a constant increase trend seen in $\mathrm{H}_{2} \mathrm{O}_{2}$ output under like voltage conditions. EC also induced a gradual ascend in $\mathrm{H}_{2} \mathrm{O}_{2}$ output, while descends $\mathrm{O}_{3}$ output in first instance at EC level 0 to $2500 \mu \mathrm{s}$ but later remained stationary at higher EC levels ( 2500 to $10000 \mu \mathrm{s})$. Like many other factors, similar pattern seen while studying $\mathrm{pH}$ effects which initially boost and later decrease in the $\mathrm{H}_{2} \mathrm{O}_{2}$ output but two inflection points for $\mathrm{O}_{3}$ output. It is concluded for the results that, $\mathrm{H}_{2} \mathrm{O}_{2}$ and $\mathrm{O}_{3}$ output can reasonably be controlled under different physico-chemical conditions, hence to attain the desired results with potential usage in chemical pollution, material handling, biomedicine and lot more etc.
\end{abstract}

Keywords: Air-water discharge, double DBD, $\mathrm{H}_{2} \mathrm{O}_{2}, \mathrm{O}_{3}$, physico-chemical.

\section{INTRODUCTION}

With the rapid development of chemical industry in recent years, a large number of chemical companies have been built constantly, hence creating the great problems of hazardous wastewaters and gases exhausted to contaminate the environment. This continuous input of the hazardous materials (gases, wastewater etc.) from chemical industry to the environment, demand a dire need to focus on proper disposal of refractory organic and inorganic compounds which pose a serious threat to the environment, human health, flora and fauna of the world.

Various conventional techniques like mechanical, chemical, and biological treatments are widely used for wastewater and exhaust gas pollution treatments from chemical industry. However, the scope of many of these processes is limited to transfer the contaminant from one phase to another, thus all end up with a secondary waste product which needs to be further dealt with $[1,2]$. Fortunately, limitations of these conventional techniques can be overcome by the so-called advanced oxidation processes (AOPs) such as photocatalysis [3], Fenton processes [4] and $\mathrm{UV} / \mathrm{H}_{2} \mathrm{O}_{2}$ [5] based on in situ generation of strong oxygen-based oxidizers $\left(\cdot \mathrm{OH}, \mathrm{H}_{2} \mathrm{O}_{2}, \mathrm{O}_{3}\right.$, $\cdot \mathrm{O}$, etc.), especially hydroxyl radical $(\cdot \mathrm{OH})$, which is among the strongest oxidizers $(2.8 \mathrm{eV})$ and potential oxidant reacts non-selectively with various types of pollutants [6].

However, the short half-life of $\cdot \mathrm{OH}$ is only $\left(10^{-6}-10^{-9} \mathrm{se}-\right.$ cond) limit the scope of its application to some extent [7,8], while on the one hand, the half-life of $\mathrm{H}_{2} \mathrm{O}_{2}$ and $\mathrm{O}_{3}$ is relatively long, i.e., the order of 10-20 minute and 16 minute respectively, under normal atmospheric pressures $[9,10]$. On the other hand, based on a certain molar ratio (the optimal molar ratio between 0.5 and 1 ), the synergic action between $\mathrm{H}_{2} \mathrm{O}_{2}$ and $\mathrm{O}_{3}$ can generate most of $\cdot \mathrm{OH}$ $\left(\mathrm{H}_{2} \mathrm{O}_{2}+\mathrm{O}_{3} \rightarrow \cdot \mathrm{OH}+\mathrm{O}_{2}+\cdot \mathrm{HO}_{2} ; \quad \mathrm{H}_{2} \mathrm{O}_{2}+2 \mathrm{O}_{3} \rightarrow 2 \cdot \mathrm{OH}+3 \mathrm{O}_{2}\right) \quad$ [11]. Furthermore, $\mathrm{OH}$ can be generate quickly by addition of different catalysts such as $\mathrm{Fe}^{2+}$ for Fenton's reactions $\left(\mathrm{Fe}^{2+}+\mathrm{H}_{2} \mathrm{O}_{2} \rightarrow \mathrm{Fe}^{3+}+\cdot \mathrm{OH}+\mathrm{OH}^{-}\right)$or ultraviolet radiation e.g., $\left(\mathrm{O}_{3}+\mathrm{H}_{2} \mathrm{O}+\mathrm{hv} \rightarrow \mathrm{O}_{2}+\mathrm{H}_{2} \mathrm{O}_{2}, \mathrm{H}_{2} \mathrm{O}_{2}+\mathrm{hv} \rightarrow 2 \cdot \mathrm{OH}\right)$ to $\mathrm{H}_{2} \mathrm{O}_{2}$ and $\mathrm{O}_{3}$ [12-14]. In a word, $\mathrm{H}_{2} \mathrm{O}_{2}$ and $\mathrm{O}_{3}$ not only can react with chemical pollutants directly, but also can be quickly yield . $\mathrm{OH}$ under certain conditions to dissociate and decompose the high concentration of refractory organic compounds due to their long half-life, easy storage and transportation.

Hence, how to induce the generation of $\mathrm{H}_{2} \mathrm{O}_{2}$ and $\mathrm{O}_{3}$ simultaneously becomes a very meaningful research, especially when dealing with chemical pollution. By comparing production in plasma with chemical methods, plasmainduced $\mathrm{H}_{2} \mathrm{O}_{2}$ and $\mathrm{O}_{3}$ generation is an environmental friendly process without using chemical reagents. For this reason, a set of air-water discharge induced by double Dielectric Barrier Discharge (double DBD) device has been designed to obtain $\mathrm{H}_{2} \mathrm{O}_{2}$ and $\mathrm{O}_{3}$ simultaneously. By keeping these views 


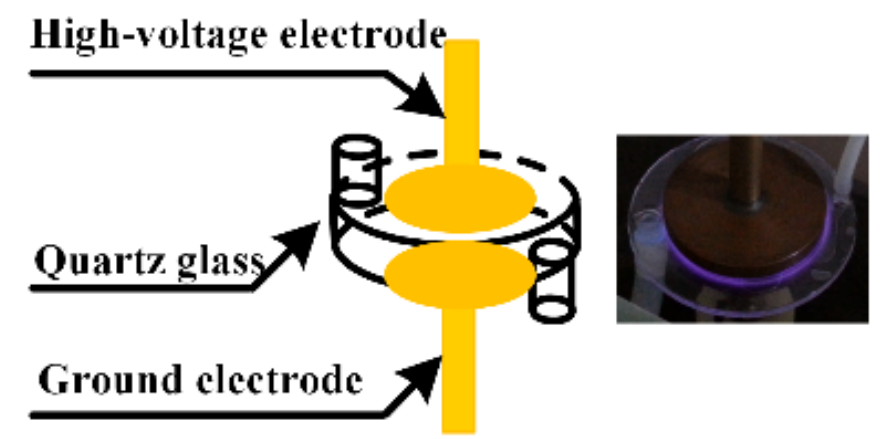

Fig. (1). Schematic drawing and photo of double DBD.

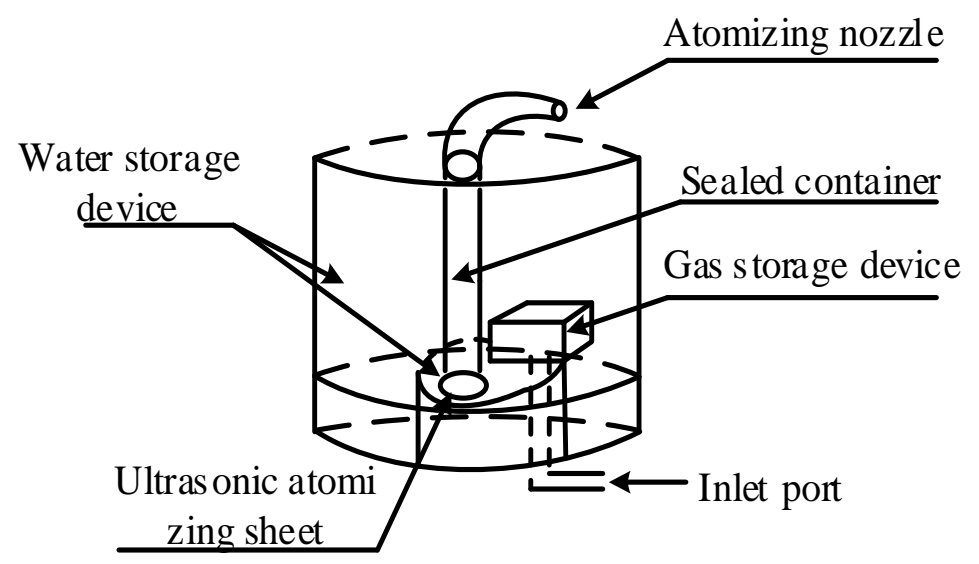

Fig. (2). Schematic diagram of ultrasonic atomizer.

in mind, we aim in the present work is to investigate the mechanism of generation from $\mathrm{H}_{2} \mathrm{O}_{2}$ and $\mathrm{O}_{3}$ along with their yield maximization conditions by double DBD. For this reason, a set of air-water discharge device induced by double Dielectric Barrier Discharge (double DBD) has been designed to obtain $\mathrm{H}_{2} \mathrm{O}_{2}$ and $\mathrm{O}_{3}$ simultaneously. By keeping these views in mind, we aim in the present work is to investigate the mechanism of generation of $\cdot \mathrm{OH}$ from $\mathrm{H}_{2} \mathrm{O}_{2}$ and $\mathrm{O}_{3}$ along with their yield maximization conditions by double DBD. Several factors, such as air cooling, atomization amount, applied voltage, $\mathrm{pH}$ value and $\mathrm{EC}$, affecting the generating of $\mathrm{H}_{2} \mathrm{O}_{2}$ and $\mathrm{O}_{3}$ were studied in detail.

\section{EXPERIMENT SECTION}

\subsection{The Structure of Double Dielectric Barrier Discharge}

The physical structure of double DBD device was shown in Fig. (1). The plasma reactor consisted of one quartz glass disc, an active and a ground electrode. The quartz glass disc was sintered with two pieces of quartz glass plates (diameter $150 \mathrm{~mm}$ and thickness $2 \mathrm{~mm}$ ), and each plate was sintered with a vent hole, leaving $0.5 \mathrm{~mm}$ gap between two pieces of quartz glass plates. In this experiment, the dielectric barrier was located between the active and the ground electrodes made of copper.

\subsection{Ultrasonic Atomizer}

Fig. (2) showed the schematic diagram of an ultrasonic atomizer designed and processed by ourselves. It is comprised of an ultrasonic atomizing sheet, its peripheral circuit, a water and gas storage separate compartments. In order to make the atomizing water smoothly inject into the plasma device from the atomizing nozzle, an inlet port with threaded connections was designed in the bottom middle of the gas storage device. First of all, the air, with certain pressure adjusted by the output pressure knob of air compressor (provided by Shanghai Greeloy Industry Co., China Ltd), was connected to a flow meter (produced by Jiangyin Keda Instrument and meter Plant from China) through an intake pipe, then it would get out from the flow meter with a predetermined flow rate through an outlet pipe, finally passing into the gas storage device through the inlet port with thread.

At the same time, in order to keep the quartz disc not broken, both the output pressure of air compressor and the flow rate must not be exceeded 1.25 bar and $200 \mathrm{~L} / \mathrm{h}$, respectively. Hence, in the present experiment, the air compressor and flow meter was fixed in 1.0 bar and $200 \mathrm{~L} / \mathrm{h}$, respectively. And the gas storage device was connected with the water storage device equipped with the ultrasonic atomizing sheet. Therefore, under the action of air pressure, the atomized micron particles produced by the ultrasonic atomizing sheet 
could walk along the sealed container, then get out through spray nozzle at the flow velocity of $200 \mathrm{~L} / \mathrm{h}$ to reach its final destination of quartz glass disc. Among them, the ultrasonic atomizer rated power was $35 \mathrm{~W}$, and distilled water (produced by Chongqing Chuandong Chemical Group Co., China Ltd) was put as the atomization liquid. The high frequency oscillation can reach up to 3 million times per second, without the generation of any water droplets, and the size of atomized particle can be almost below $5 \mu \mathrm{m}$.

\subsection{Experimental Apparatus and Measurement System}

The schematic diagram of the whole experimental system was showed in Fig. (3). The CTP-2000K low temperature plasma power supply manufactured by Nanjing Suman Electronic Co., China Ltd was selected as the driving power of $\mathrm{DBD}$, with $0 \sim 30 \mathrm{kV}$ effective value range of output voltage, and $10 \mathrm{kHz}$ power center frequency. In Fig. (3), Rm and $\mathrm{Cm}$ was denoted $50 \Omega$ non-inductance resistance and $0.47 \mu \mathrm{F}$ capacitance, respectively, which measured discharge current and discharge charge. Tek P6015A was used to measure the applied voltage in the experiment. Tek DPO2014 digital oscilloscope was used to obtain the oscillogram of discharge voltage and discharge current.

1. High-voltage electrode; 2. Quartz glass; 3. Highvoltage electrode; 4 . Axial fan; 5 . High voltage power supply;

6. High voltage probe; 7. Oscilloscope; 8. Computer;

9 Ozone Monitor; 10. Gas washing bottle; 11. Air compressor;

12. Switch valve; 13. Flow meter; 14. Ultrasonic atomizer;

\section{Atomized water input; 16 . Atomized water output}

\subsection{Reagents and Experimental Method}

HM digital AP-2 type digital water quality tester manufactured from South Korea was used to measure the EC of atomized water, which was changed by different volume of $0.01 \mathrm{~mol} / \mathrm{L}$ potassium chloride $(\mathrm{KCl}$, Analytical Reagent, produced by Chengdu Kelong Chemical Co., China Ltd) added to the distilled water. And PH meter (Model: PHH-5012, produced by OMEGA company) was used to measure the $\mathrm{PH}$ value of atomized water, which was changed by different volume of $0.1 \mathrm{~mol} / \mathrm{L}$ concentrated sulfuric acid $\left(\mathrm{H}_{2} \mathrm{SO}_{4}\right)$ and $0.1 \mathrm{~mol} / \mathrm{L}$ sodium hydroxide $(\mathrm{NaOH}$, Analytical Reagent, also produced by Chongqing Chuandong chemical group Co., China Ltd) added to the distilled water. Laboratory Electronic Balance (Model: PPT-A+200, produced by Huazhi scientific instrument Co., China Ltd) was used to weigh different chemicals with the accuracy of upto $1 \mathrm{mg}$.

\subsubsection{The Testing of Hydrogen Peroxide Concentration}

$\mathrm{H}_{2} \mathrm{O}_{2}$ was measured in liquid by using the $\mathrm{H}_{2} \mathrm{O}_{2}$ detector (Model: GDYS-102SC, Changchun Jilin University, Little Swan Instruments Co., China Ltd.). In order to measure the concentration of $\mathrm{H}_{2} \mathrm{O}_{2}$ produced by DDBD, $\mathrm{H}_{2} \mathrm{O}_{2}$ was collected by a gas washing bottle filled with $30 \mathrm{ml}$ distilled water. After 15 minutes, the plasma device stop working immediately, and then it can be measured by the volume of the collected water in the gas washing bottle, and finally it can detect the concentration of $\mathrm{H}_{2} \mathrm{O}_{2}$ by the detector.

\subsubsection{The Testing of Ozone Concentration}

The $\mathrm{O}_{3}$ was measured in gas phase by using the specific detector (Model: DR70C-O ${ }_{3}$, Shenzhen Wosaite Technology Co., China Ltd.) during this experiment. The data was taken by $\mathrm{O}_{3}$ detector and constantly was transmitted through RS232 protocol to the computer.

\section{THE EXPERIMENTAL RESULTS AND DISCUS- SION}

During our experimentation, unless otherwise specified we used the distilled water as atomized water. In order to reduce any error and ensure the accuracy of experimental conclusions, the data of multiple repeats taken to take averages.

\subsection{The Influence of Atomization Amount}

Fig. (4) showed the change curve of $\mathrm{H}_{2} \mathrm{O}_{2}$ and $\mathrm{O}_{3}$ production with atomization amount raised when the voltage was equal to $34 \mathrm{kV}$. The atomization amount is ranged from

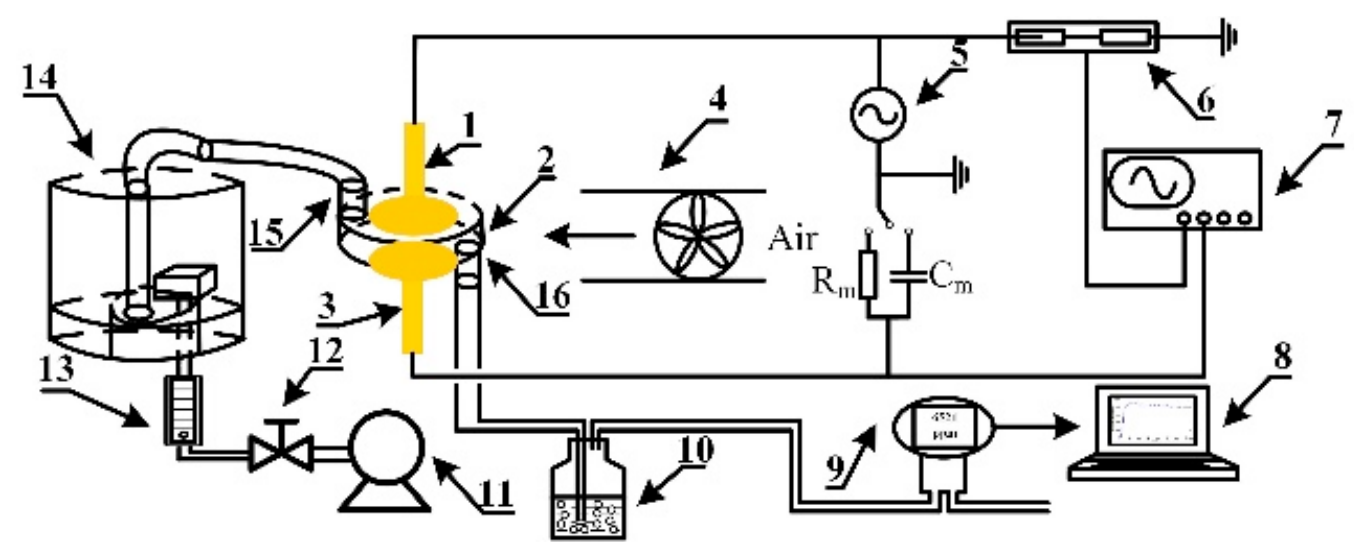

Fig. (3). Schematic diagram of the experimental setup. 


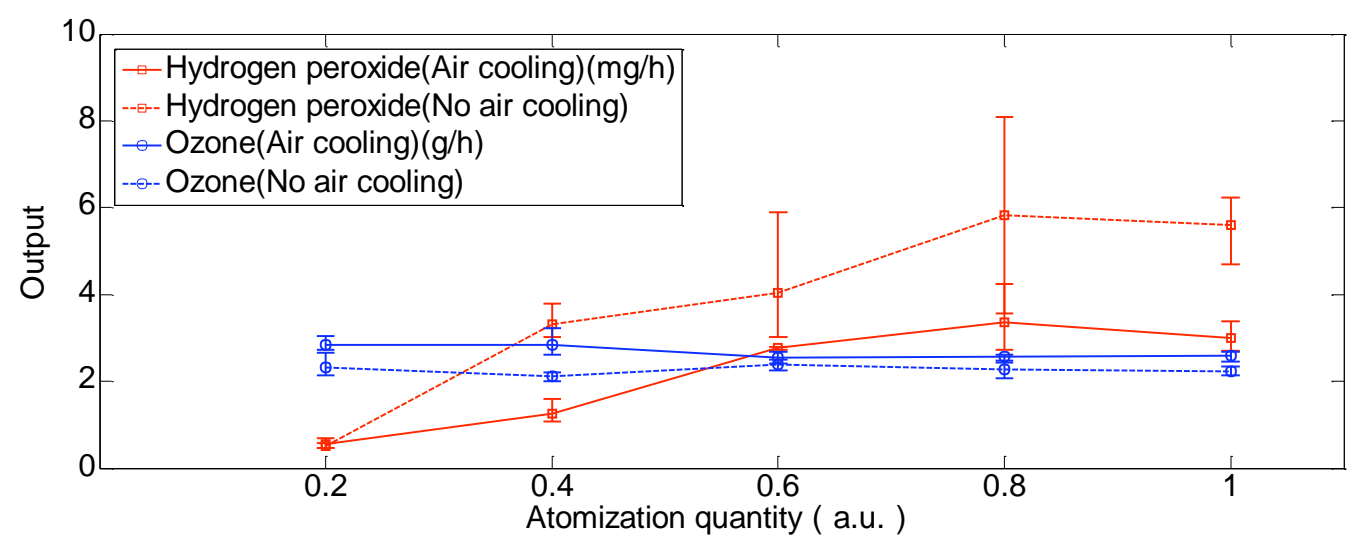

Fig.(4). The change curve of hydrogen peroxide and ozone output with atomization amout.

$0.2-1.0$, and the later is the highest amount $(0.4 \mathrm{~L} / \mathrm{h})$. It is evident by Fig. (4) that with increasing atomization amount slightly reduced the $\mathrm{O}_{3}$ output, while initially $\mathrm{H}_{2} \mathrm{O}_{2}$ output increase that later decreased. Upon forced air cooling of the electric discharge device, it enhanced $\mathrm{O}_{3}$ output, while $\mathrm{H}_{2} \mathrm{O}_{2}$ output declined under the same atomization amount, but how this different curve between $\mathrm{O}_{3}$ and $\mathrm{H}_{2} \mathrm{O}_{2}$ happened are still to be explored?

The solid reasons for this can be made by studying the mechanism of formation of $\mathrm{H}_{2} \mathrm{O}_{2}$ and $\mathrm{O}_{3}$ during this experiment. $\mathrm{H}_{2} \mathrm{O}_{2}$ was generated mainly the electron energy and water molecules (equations (1-5)). [9, 13-16]. Therefore, with the increase of atomization amount from 0.2 to 0.8 , there were more water molecules appeared in the discharge space, increasing the probability of collision between highenergy electrons and water molecules to generate $\mathrm{H}_{2} \mathrm{O}_{2}$. But in ultrasonic atomizer at the highest atomization level, electrons would be adsorbed by water molecules in the discharge space because water molecules were in the electronegative gas phase. It declined the probability of collision between high-energy electrons and water molecules, simply $\mathrm{H}_{2} \mathrm{O}_{2}$ output start declining as the atomization value approached near 1.0.

$$
\begin{aligned}
& \mathrm{e}+2 \mathrm{H}_{2} \mathrm{O} \rightarrow \mathrm{H}_{2} \mathrm{O}_{2}+\mathrm{H}_{2}+\mathrm{e} \\
& \mathrm{e}^{-}+\mathrm{H}_{2} \mathrm{O} \rightarrow \cdot \mathrm{OH}+\cdot \mathrm{H}+\mathrm{e}^{-} \\
& \mathrm{O}+\mathrm{H}_{2} \mathrm{O} \rightarrow \cdot \mathrm{OH}+\cdot \mathrm{OH} \\
& \mathrm{H}_{2} \mathrm{O}+\mathrm{hv} \rightarrow \cdot \mathrm{OH}+\mathrm{H} \\
& \cdot \mathrm{OH}+\cdot \mathrm{OH} \rightarrow \mathrm{H}_{2} \mathrm{O}_{2}
\end{aligned}
$$

The overall ozone generation can be summarized according to the following reactions (6)-(10) in the experiment [1618]. These equations (6-10) showed clearly that the production of $\mathrm{O}_{3}$ was determined by the electron energy and the level of oxygen. It is well known that the higher humidity the less $\mathrm{O}_{3}$ output, in addition, it was observed that the generation of both $\mathrm{O}_{3}$ and $\mathrm{H}_{2} \mathrm{O}_{2}$ were dependent on the excited state energy of electrons. By applying the same voltage level, both the energy and number of electrons remained constant at the given time there exist high probability of electronic collisions with water molecules that gives rise more $\mathrm{H}_{2} \mathrm{O}_{2}$, hence less chances of electronic collisions with oxygen $\left(\mathrm{O}_{2}\right)$ molecules to generate oxygen atom. Therefore, $\mathrm{O}_{3}$ output slightly but steadily reduced with the increase of atomization amount.

$$
\begin{aligned}
& \mathrm{e}+\mathrm{O}_{2} \rightarrow \mathrm{e}+\mathrm{O}\left({ }^{3} \mathrm{P}\right)+\mathrm{O}\left({ }^{3} \mathrm{P}\right) \\
& \mathrm{e}+\mathrm{O}_{2} \rightarrow \mathrm{e}+\mathrm{O}\left({ }^{3} \mathrm{P}\right)+\mathrm{O}\left({ }^{1} \mathrm{D}\right) \\
& \mathrm{e}+\mathrm{O}_{2} \rightarrow \mathrm{e}+\mathrm{O}+\mathrm{O}\left({ }^{1} \mathrm{D}\right) \\
& \mathrm{e}+\mathrm{O}_{2} \rightarrow \mathrm{O}^{+}+2 \mathrm{e}+\mathrm{O}\left({ }^{1} \mathrm{D}\right) \\
& \mathrm{O}+\mathrm{O}_{2} \rightarrow \mathrm{O}_{3}
\end{aligned}
$$

If the electric discharge device was not given forced air cooling compared to the electric discharge device forced air cooling, $\mathrm{O}_{3}$ was diminished due to a excessive heat generated in the process of plasma discharge under the same amount of atomization.

It is well known that rate of decomposition of $\mathrm{O}_{3}$ and converting it into $\mathrm{O}_{2}$ was accelerated by increasing the temperature, e.g., $270{ }^{\circ} \mathrm{C}$ can quickly convert $\mathrm{O}_{3}$ to oxygen $\left(2 \mathrm{O}_{3} \rightarrow 3 \mathrm{O}_{2}+285 \mathrm{~kJ}\right)$. So, when the fan was in operation, the $\mathrm{O}_{3}$ decomposition rate lessened because of the decline in temperature of the discharge device due to the rapid air flow from axial fan. In absence of air cooling system, the decreased output of $\mathrm{O}_{3}$ would also resulted in more $\mathrm{H}_{2} \mathrm{O}_{2}$ production. Because $\mathrm{O}$ was involved in the generation of $\mathrm{O}_{3}$ and $\mathrm{H}_{2} \mathrm{O}_{2}$ (equations (3), (10)), but the former can also be obtained according to the equation (10). Consequently, if $\mathrm{O}_{3}$ output was to be diminished, much more $\mathrm{O}_{2}$ and $\mathrm{O}$ would be generated in the discharge space results in an increase in the probability of producing $\mathrm{H}_{2} \mathrm{O}_{2}$ (equations (3), (5)). In general, compared to the electric discharge device without air cooling $\mathrm{O}_{3}$ output enhanced, while $\mathrm{H}_{2} \mathrm{O}_{2}$ production was declined when the electric discharge device was given the air cooling under the same atomization amount and electrode voltage.

\subsection{The Influence of Electrode Voltage}

It was observed that the change curve of $\mathrm{H}_{2} \mathrm{O}_{2}$ and $\mathrm{O}_{3}$ output with the electrode voltage when the value of 


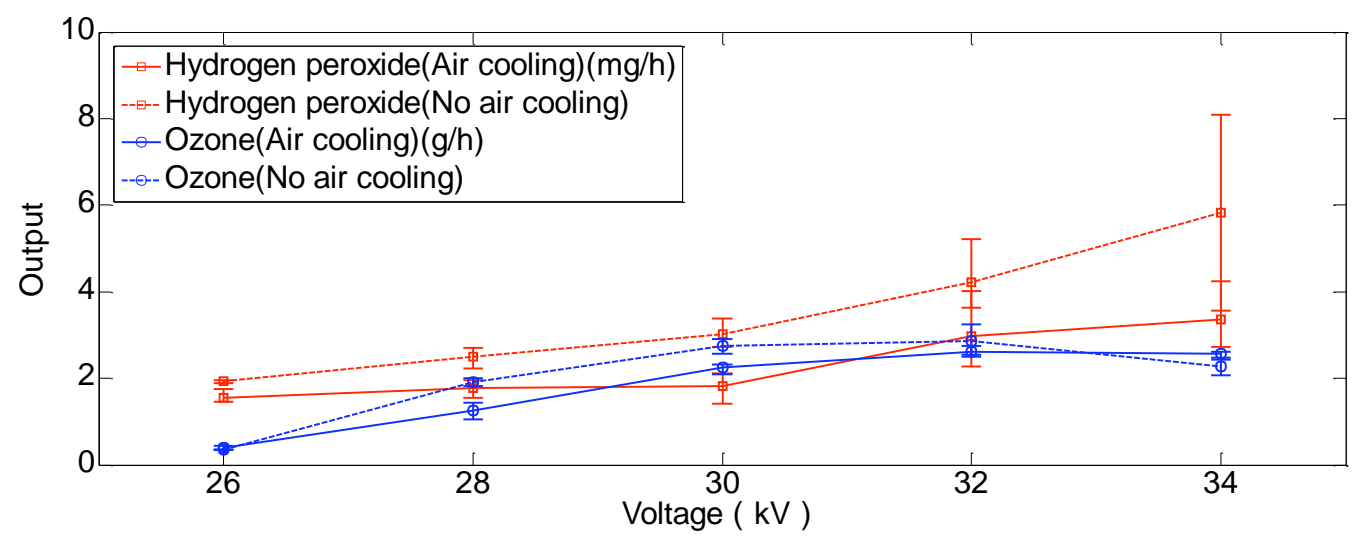

Fig. (5). The change curve of hydrogen peroxide and ozone output with electrode voltage.

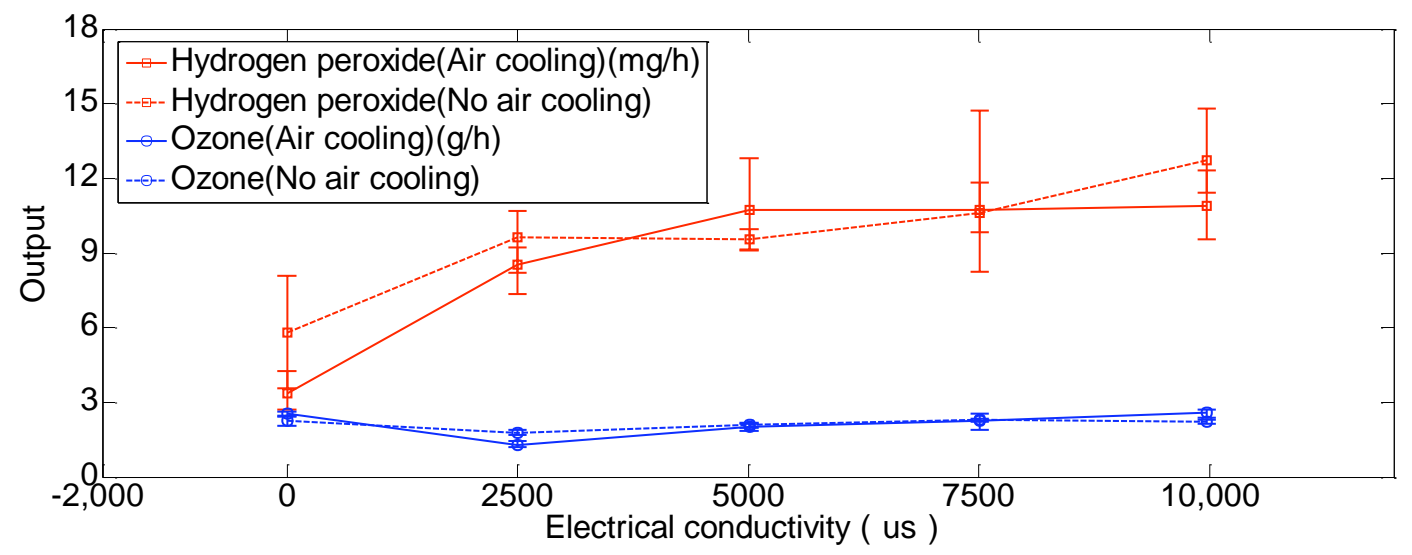

Fig. (6). The change curve of hydrogen peroxide and ozone output with conductivity.

atomization amount was fixed in 0.8 as shown in Fig. (5). Whether the electric discharge device was forced air cooling or not, both $\mathrm{H}_{2} \mathrm{O}_{2}$ and $\mathrm{O}_{3}$ production increases with the electrode voltage raises from $26 \mathrm{kV}$ to $34 \mathrm{kV}$, besides $\mathrm{O}_{3}$ production would be declined when the electrode voltage was equal to $34 \mathrm{kV}$ and the electric discharge device was not forced air cooling.

The possible reasons are numerous for this phenomenon. With the increase of electrode voltage, the strength of the electric field would be improved, and more power would be injected into the reactor, results in abrupt enhancement of both the speed and the energy of free electrons. Therefore, more and more active species such as $\mathrm{H}_{2} \mathrm{O}_{2}$ and $\mathrm{O}_{3}$ produced effectively (equations (1-10)), due to the bombardment of high energy electrons. But when the electric discharge device was not forced to air cooling, $\mathrm{O}_{3}$ production would be declined with applied voltage increased from $32 \mathrm{kV}$ to $34 \mathrm{kV}$. Because, at this moment, the electrode voltage was so high that Joule $(\mathrm{J})$ unit heat would be consumed by the electrode during the discharge process. Of course, heat had additive effects, the result was due to the temperature risen and hence more $\mathrm{O}_{3}$ converted into $\mathrm{O}_{2}\left(2 \mathrm{O}_{3} \rightarrow 3 \mathrm{O}_{2}+285 \mathrm{~kJ}\right)$.

Under the same amount of atomization and electrode voltage (from $26 \mathrm{kV}$ to $32 \mathrm{kV}$ ), compared to the electric discharge device not forced air cooling, both $\mathrm{H}_{2} \mathrm{O}_{2}$ and $\mathrm{O}_{3}$ output would be reduced when the electrode was forced air cooling, which was inconsistent with the previous variations shown in Fig. (4). It may be when electrode voltage was below $32 \mathrm{kV}$, less $\mathrm{J}$ heat was generated by the discharge. Therefore, especially when the electric discharge device was forced air cooling, the temperature of quartz glass disc was declined, and thus atomized particles were more easily formed from water and much more high-energy electrons could readily be adsorbed, probably lead to decline highenergy electrons coated with water molecules and oxygen. Hence, under similar experimental conditions, compared with the electric discharge device forced with air cooling, both $\mathrm{H}_{2} \mathrm{O}_{2}$ and $\mathrm{O}_{3}$ production would be increased and this never observed when the electric discharge device without forced air cooling.

\subsection{The Influence of EC}

The EC of distilled water, as the atomization solution, was changed by different volumes of $0.01 \mathrm{~mol} / \mathrm{L}$ potassium chloride $(\mathrm{KCl})$ added to distilled water. As Fig. (6) showed the change curve of $\mathrm{H}_{2} \mathrm{O}_{2}$ output with $\mathrm{EC}$ was completely inconsistent with $\mathrm{O}_{3}$. In other words, with the increase of EC, $\mathrm{H}_{2} \mathrm{O}_{2}$ output increased gradually, while $\mathrm{O}_{3}$ output reduced first at EC 0 to $2500 \mu$ s and then remained static at EC from 2500 to $10000 \mu$ s. 


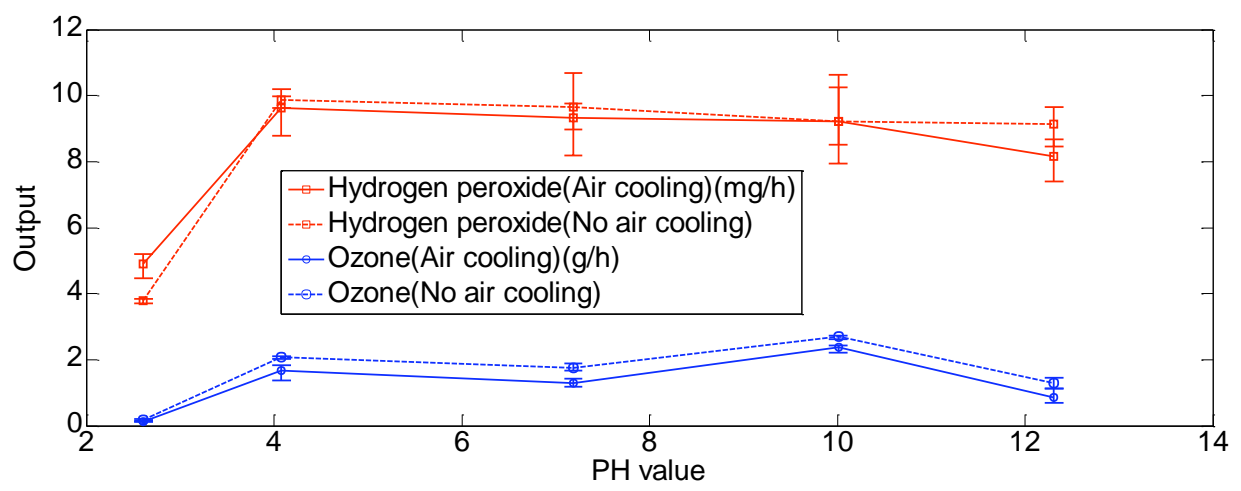

Fig. (7). The change curve of hydrogen peroxide and ozone output with PH value.

Indeed, under the same voltage and the electrode spacing the leakage current of the solution was increased as the EC of the solution raised, so that the actual voltage between the electrodes was reduced thereby weaken the discharge. The experimental result showed that the amount of active species $\left(\mathrm{H}_{2} \mathrm{O}_{2}\right.$ and $\left.\mathrm{O}_{3}\right)$ generated by discharge would be reduced with the increase in EC. As Fig. (6) showed, $\mathrm{O}_{3}$ output started to reduce as the EC was increased from 0 to $2500 \mu$ s. Then $\mathrm{O}_{3}$ output remained stationary even at higher EC values ( $>$ $2500 \mu \mathrm{s})$. But, comparing with $\mathrm{O}_{3}$ output, it was found totally different for the change curve of $\mathrm{H}_{2} \mathrm{O}_{2}$ output when $\mathrm{EC}$ was raised. In fact, $\mathrm{H}_{2} \mathrm{O}_{2}$ output did not fall but increase with rise of EC. It was well known that the strength of the discharge was weakened due to the increase in EC, but this rise in EC enhanced the level of UV radiation. Therefore, in our opinion, $\mathrm{H}_{2} \mathrm{O}_{2}$ was generated primarily by the following equation (11) $[13,19,20]$, because UV radiation overwhelmed, so that $\mathrm{H}_{2} \mathrm{O}_{2}$ output increased gradually with the EC was increased. At the same time, although an $\mathrm{O}_{3}$ molecule was involved in the generation of $\mathrm{H}_{2} \mathrm{O}_{2}$, an $\mathrm{O}_{2}$ molecule will be also generated, so the whole ozone production was not greatly affected according to equation (10).

$\mathrm{O}_{3}+\mathrm{H}_{2} \mathrm{O}+\mathrm{hv} \rightarrow \mathrm{O}_{2}+\mathrm{H}_{2} \mathrm{O}_{2}$

Whether the electric discharge device was forced air cooling or not, there was no significant change for both $\mathrm{H}_{2} \mathrm{O}_{2}$ and $\mathrm{O}_{3}$ output. Because as the EC increased, not only the strength of the discharge would be weak, but also J heat consumed by the electrode would be reduced at the same time, because the electrode voltage was always up to a maximum of $34 \mathrm{kV}$, so it was no possible that a sufficient quantity of liquid water formed, may finally be leading to the temperature of quartz glass disc dropped a little when increasing EC. Therefore, there was no significant effect on the production of $\mathrm{O}_{3}$ and $\mathrm{H}_{2} \mathrm{O}_{2}$ when the electric discharge device was forced air cooling.

\subsection{The Influence of PH Value}

The $\mathrm{pH}$ value was adjusted to 1:10 (by volume) with $\mathrm{H}_{2} \mathrm{SO}_{4}$ and $0.01 \mathrm{~mol} / \mathrm{L} \mathrm{NaOH}$. When the $\mathrm{pH}$ was changed by adding $\mathrm{H}_{2} \mathrm{SO}_{4}$ and $\mathrm{NaOH}$, the $\mathrm{EC}$ of solution was also changed at the same time. So, in order to ensure the consistency of experimental conditions, different volumes of
$0.01 \mathrm{~mol} / \mathrm{L} \mathrm{KCl}$ would be added to the solution to keep the $\mathrm{EC}$ at constant level (equal to $2500 \mu \mathrm{s}$ ), thus eliminating the interference of $\mathrm{EC}$ after $\mathrm{pH}$ value was altered each time.

At $\mathrm{pH} 4.0, \mathrm{H}^{+}$ions, $\mathrm{OH}^{-}$ions and $\mathrm{O}_{3}$ molecules existed in solution, and therefore caused the different chemical reaction (equations (12-18)) taken place and resulted in higher $\mathrm{H}_{2} \mathrm{O}_{2}$ generation $[11,14,21]$.

$\mathrm{O}_{3}+\mathrm{OH}^{-} \rightarrow \cdot \mathrm{O}_{2}^{-}+\cdot \mathrm{HO}_{2}$

$\cdot \mathrm{HO}_{2} \rightarrow \cdot \mathrm{O}_{2}^{-}+\mathrm{H}^{+}$

$\mathrm{O}_{3}+\mathrm{O}_{2}^{-} \rightarrow \cdot \mathrm{O}_{3}{ }^{-}+\mathrm{O}_{2}$

$\cdot \mathrm{O}_{3}{ }^{-}+\mathrm{H}^{+} \rightarrow \cdot \mathrm{HO}_{3}$

$\cdot \mathrm{HO}_{3} \rightarrow \cdot \mathrm{OH}+\mathrm{O}_{2}$

$\cdot \mathrm{OH}+\cdot \mathrm{OH} \rightarrow \mathrm{H}_{2} \mathrm{O}_{2}$

$\mathrm{H}_{2} \mathrm{O} \leftrightarrow \mathrm{H}^{+}+\mathrm{OH}^{-}$

However, at lesser $\mathrm{pH}$ levels $(<4.0)$, there were more and more $\mathrm{H}^{+}$ions in solution, thus causing the reverse reaction (equation (18)), resulting in the rapid reduction of $\mathrm{OH}^{-}$ions and producing much more water molecules. Eventually, as shown in Fig. (7), $\mathrm{H}_{2} \mathrm{O}_{2}$ and $\mathrm{O}_{3}$ output would be reduced rapidly when $\mathrm{pH}$ value was approximately equal to 2.61 .

On the other hand, with higher $\mathrm{pH}$ levels $(\mathrm{pH}>4)$, the concentration of hydroxide ions became higher and higher, thus the generation rate of hydroxyl radical was improved by the hydroxide ions because the hydroxide ions were hydroxyl radical's initiator. In other words, more and more hydrox$\mathrm{yl}$ radical are produced when $\mathrm{pH}$ was greater than 4.0. Therefore, both hydroxyl radical and $\mathrm{H}_{2} \mathrm{O}_{2}$ were higher to quickly trigger the follow equation (19) to take place.

$\mathrm{H}_{2} \mathrm{O}_{2}+\cdot \mathrm{OH} \rightarrow \mathrm{H}_{2} \mathrm{O}+\cdot \mathrm{HO}_{2}$

However, with $\mathrm{pH}$ continuing to increase, $\mathrm{H}_{2} \mathrm{O}_{2}$ would react with $\mathrm{O}_{3}$ in an alkaline environment $(\mathrm{pH}=12)$. The related chemical reactions were taken place [7-8].

$$
\begin{aligned}
& \mathrm{H}_{2} \mathrm{O}_{2}+2 \mathrm{O}_{3} \rightarrow 2 \cdot \mathrm{OH}+3 \mathrm{O}_{2} \\
& \mathrm{H}_{2} \mathrm{O}_{2}+\mathrm{O}_{3} \rightarrow \cdot \mathrm{OH}+\mathrm{O}_{2}+\cdot \mathrm{HO}_{2} \\
& \mathrm{H}_{2} \mathrm{O}_{2} \rightarrow \mathrm{HO}_{2}{ }^{-}+\mathrm{H}^{+}
\end{aligned}
$$


Thus, it was clear that minimum $\mathrm{H}_{2} \mathrm{O}_{2}$ output is correlated with $\mathrm{pH}$ increased from acidity to basicity $(\mathrm{pH} 4.0$ to 12.0). As was known to all, under alkaline conditions (for example $\mathrm{pH}=10$ ), the $\mathrm{O}_{3}$ solubility became smaller and - $\mathrm{OH}$ would quickly dissociate into less active $\mathrm{O}_{2}^{-}$, resulting in $\mathrm{O}_{3}$ utilization decline. Based on the above discussion, the maximum $\mathrm{O}_{3}$ output would be turn up when $\mathrm{pH}$ was equal to 10. However, under strong alkaline conditions $(\mathrm{pH} \geq 12.0)$, more and more $\mathrm{O}_{3}$ would be taken part in the following chemical reactions $(23-26)[21,22]$. Therefore, the $\mathrm{O}_{3}$ production started to fall when $\mathrm{pH}$ was greater than 12.0.

$\mathrm{O}_{3}+\mathrm{OH}^{-} \rightarrow \mathrm{O}_{2}^{-}+\cdot \mathrm{HO}_{2}$

$\mathrm{O}_{3}+3 \cdot \mathrm{HO}_{2} \rightarrow 3 \cdot \mathrm{OH}+3 \mathrm{O}_{2}$

$\mathrm{O}_{3}+\mathrm{OH}^{-} \rightarrow \mathrm{OH}^{2-}+\mathrm{O}_{2}$

$\mathrm{O}_{3}+\mathrm{OH}^{2-} \rightarrow \cdot \mathrm{OH}+\mathrm{O}^{2-}+\mathrm{O}_{2}$

\section{CONCLUSION}

A set of air-water discharge induced by double DBD device had been designed to obtain $\mathrm{H}_{2} \mathrm{O}_{2}$ and $\mathrm{O}_{3}$ simultaneously. It had been studied the change rules of $\mathrm{H}_{2} \mathrm{O}_{2}$ and $\mathrm{O}_{3}$ production effected by different experimental conditions such as air cooling, spray amount, electrode voltage, $\mathrm{pH}$ value and conductivity. The specific conclusions were as follows:

(1) With increasing atomization amount slightly reduced the $\mathrm{O}_{3}$ output, while initially $\mathrm{H}_{2} \mathrm{O}_{2}$ output increase that later decreased. Upon forced air cooling of the electric discharge device, it enhanced $\mathrm{O}_{3}$ output, while $\mathrm{H}_{2} \mathrm{O}_{2}$ output declined under the same atomization amount.

(2) Whether the electric discharge device was forced air cooling or not, both $\mathrm{H}_{2} \mathrm{O}_{2}$ and $\mathrm{O}_{3}$ production increases with the electrode voltage raises from $26 \mathrm{kV}$ to $34 \mathrm{kV}$, besides $\mathrm{O}_{3}$ production would be declined when the electrode voltage was equal to $34 \mathrm{kV}$ and the electric discharge device was not forced air cooling.

(3) With the increase of EC, $\mathrm{H}_{2} \mathrm{O}_{2}$ output increased gradually, while $\mathrm{O}_{3}$ output reduced first at EC 0 to $2500 \mu \mathrm{s}$ and then remained static at EC from 2500 to $10000 \mu \mathrm{s}$. At the same time, whether the electric discharge device was forced air cooling or not, there was no significant change for both $\mathrm{H}_{2} \mathrm{O}_{2}$ and $\mathrm{O}_{3}$ output.

(4) With $\mathrm{pH}$ value increased, $\mathrm{H}_{2} \mathrm{O}_{2}$ output increased first then decreased, while it had appeared two inflection points for $\mathrm{O}_{3}$ output.

In a word, it was concluded that the highest $\mathrm{H}_{2} \mathrm{O}_{2}$ output was in the experimental condition include atomization amount, voltage applied, $\mathrm{EC}$ and $\mathrm{pH}$ value should be equal to $0.8,34 \mathrm{kV}, 9999,4$ respectively in the case of not forcing air cooling. And when the setup was forced air cooling and atomization amount, electrode voltage, $\mathrm{EC}, \mathrm{pH}$ value were separately equal to $0.2,34 \mathrm{kV}, 0,10$, which was very favorable for $\mathrm{O}_{3}$ production. Therefore, these conclusions are of great for how to obtain $\mathrm{OH}$ and explore the factors to maximize the number of $\cdot \mathrm{OH}$ production. At the same time, $\mathrm{H}_{2} \mathrm{O}_{2}$ and $\mathrm{O}_{3}$ output can be reasonably controlled by changing different aforesaid experimental factors to meet different requirements in application domain, such as chemical pollution, material handling, biomedicine, etc..

\section{CONFLICT OF INTEREST}

The authors confirm that this article content has no conflict of interest.

\section{ACKNOWLEDGEMENTS}

This work was supported by National Natural Science Foundation of China under contract 51407020, National Natural Science Foundation of Chongqing City under contract cstc2013jcyjA20005, and the Fundamental Research Funds for the Central Universities under contract CDJZR14155501.

\section{REFERENCES}

[1] O. J. Hao, H. Kim, and P. C. Chiang, "Decolorization of wastewater," Critical Reviews in Environmental Science and Technology, vol. 30, pp. 449-505, 2000.

[2] S. T. Ong, P. S. Keng, W. N. Lee, S. T. Ha, and Y. T. Hung, "Dye waste treatment," Water, vol. 3, pp. 157-176, 2011.

[3] A. Kar, Y. R. Smith, and V. Subramanian, "Improved photocatalytic degradation of textile dye using titanium dioxide nanotubes formed over titanium wires," Environmental Science \& Technology, vol. 43, pp. 3260-3265, 2009.

[4] F. AlMomani, D. W. Smith, and M. G. El-Din, "Degradation of cyanobacteria toxin by advanced oxidation processes," Journal of Hazardous Materials, vol. 150, pp. 238-249, 2008.

[5] M. K. Dail, and S. P. Mezyk, "Hydroxyl-radical-induced degradative oxidation of blactam antibiotics in water: absolute rate constant measurements," The Journal of Chemical Physics A, vol. 114, pp. 8391-8395, 2010.

[6] M. Magureanu, D. Piroi, and N. B. Mandache, "Degradation of antibiotics in water by non-thermal plasma treatment," Water Research, vol. 45, pp. 3407-3416, 2011.

[7] W. A. Pryor, "Oxy-radicals and related species: their formation, lifetimes, and reactions," Annual Review of Physiology, vol. 48, pp. 657-667, 1986.

[8] L. Forni, D. Bahnemann, and E. J. Hart, "Mechanism of the hydroxide ion-initiated decomposition of ozone in aqueous solution," Journal of Physical Chemistry C, vol. 86, pp. 255-259, 1982.

[9] J. Staehelin, and J. Hoigne, "Decomposition of ozone in water: rate of initiation by hydroxide ions and hydrogen peroxide," Environmental Science \& Technology, vol. 16, pp. 676-681, 1982.

[10] R. Zika, and E. Saltzman, "Interaction of ozone and hydrogen peroxide in water: implications for analysis of $\mathrm{H}_{2} \mathrm{O}_{2}$ in air," Geophysical Research Letters, vol. 9, pp. 231-234, 1982.

[11] Y. H. Yu, J. Ma, and Y. J. Hou, "Degradation of 2, 4dichlorophenoxyacetic acid in water by ozone hydrogen peroxide process," Journal of Environmental Sciences-China, vol. 18, pp. 1043-1049, 2006.

[12] J. J. Pignatello, E. Oliveros, and A. MacKay, "Advanced Oxidation Processes for Organic Contaminant Destruction Based on the Fenton Reaction and Related Chemistry," Critical Reviews in Environmental Science and Technology, vol. 36, pp. 1-84, 2006.

[13] D. R. Grymonpré, A. K. Sharma, W. C. Finney, and B. R. Locke, "The role of Fenton's reaction in aqueous phase pulsed streamer corona reactors," Chemical Engineering Journal, vol. 82, pp. 189$207,2001$.

[14] A. A. Joshi, B. R. Locke, and P. Arce, "Formation of hydroxyl radicals, hydrogen peroxide and aqueous electrons by pulsed streamer corona discharge," Journal of Hazardous Materials, vol. 41, pp. 3-30, 1995. 
[15] T. Sugiarto, S. Ito, T. Ohshima, M. Sato, and J. D. Skalny, "Oxidative decoloration of dyes by pulsed discharge plasma in water," Journal of Electrostatics, vol. 58, pp. 135-145, 2003.

[16] M. Elsawah, H. H. A. Ghafar, N. N. Morgan, S. Hassaballa, A. Samir, F. F. Elakshar, and A. A. Garamoon, "Corona discharge with electrospraying system for phenol removal from water," IEEE Transactions on Plasma Science, vol. 40, pp. 29-33, 2012.

[17] M. Magureanu, D. Piroi, and N. B. Mandache, "Degradation of antibiotics in water by non-thermal plasma treatment," Water Research, vol. 45, pp. 3407-3416, 2011.

[18] A. A. Garamoon, F. F. Elakshar, A. M. Nossair, and F. F. Kotp, "Experimental study of ozone synthesis," Plasma Sources Science and Technology, vol. 11, pp. 254-259, 2002.

[19] M. Anpilov, E. M. Barkhudarov, Y. B. Bark, Y. V. Zadiraka, M. Christofi, Y. N. Kozlov, I. A. Kossyi, V. A. Kop'ev, V. P. Silakov,
M. I. Taktakishvili, and S. M. Temchin, "Electric discharge in water as a source of UV radiation, ozone and hydrogen peroxide," Journal of Physics D-Applied Physics, vol. 34, pp. 993-999, 2001.

[20] G. R. Peyton, and W. H. Glaze, "Destruction of pollutants in water with ozone in combination with ultraviolet radiation.3 Photolysis of aqueous ozone," Environmental Science \& Technology, vol. 21, pp. 761-767, 1988

[21] Y. Matsui, N. Takeuchi, K. Sasaki, R. Hayashi, and K. Yasuoka, "Experimental and theoretical study of acetic-acid decomposition by a pulsed dielectric-barrier plasma in a gas-liquid two-phase flow," Plasma Sources Science and Technology, vol. 20, p. 034015, 2011.

[22] R. Locke, and K. Y. Shih, "Review of the methods to form hydrogen peroxide in electrical discharge plasma with liquid water," Plasma Sources Science and Technology, vol. 20, p. 034006, 2011.

Received: October 16, 2014

Revised: December 23, 2014

Accepted: December 31, 2014

(C) Kun et al.; Licensee Bentham Open.

This is an open access article licensed under the terms of the Creative Commons Attribution Non-Commercial License (http://creativecommons.org/licenses/by$\mathrm{nc} / 3.0 /$ ) which permits unrestricted, non-commercial use, distribution and reproduction in any medium, provided the work is properly cited. 